\title{
MTV, a única com design pós-moderno: Análise da influência da Pós- modernidade nas vinhetas da MTV.
}

\author{
MTV, the only with postmodern design: Analysis of the Postmodernism influence in \\ MTV's motion graphics.
}

Guilherme Lyra

MTV, design, Pós-Modernidade, vinhetas.

\begin{abstract}
Este artigo é um estudo estético das vinhetas institucionais do canal brasileiro MTV e tem a finalidade de mostrar que essas peças gráficas, muitas vezes classificadas de 'loucas', se enquadram em uma linguagem complexa: a estética pós-moderna. As vinhetas selecionadas para este estudo foram gravadas entre junho de 2004 e fevereiro de 2005 do sinal da MTV Brasil e analisadas com base nos estudos da sociedade pósmoderna de David Harvey (2000) e nos estudos de design e estética de Richard Hollis (2001) e Rudinei Koop (2002).
\end{abstract}

MTV, design, Postmodernism, motion graphics.

This article is an aesthetical study about institutional motion graphics of MTV Brazil and intends to show this video works, sometimes considered 'crazy', have a complex language: the postmodern aesthetics. The video works that were selected for this study, between June 2005 and February 2005 and analyzed based on the postmodern society studies by David Harvey (2000) and the design and aesthetical studies by Richard Hollis (2001) and Rudinei Koop (2002).

\section{Introdução}

O estudo de aspectos pós-modernos é tão complexo quanto a própria Pós-Modernidade, pois são suas principais características a instabilidade, a transitoriedade, a ausência de linearidade e rigidez sobre até mesmo o que é pós-moderno. Para entender este tempo caótico, é necessário olhar para a época que o precede e que dele difere por conceitos básicos: a Modernidade. Segundo David Harvey (2000), durante a Modernidade o mundo esteve empenhado em quebrar o vínculo com a história passada. Houve o processo de 'destruição criativa' que defendia o surgimento do moderno pela destruição do antigo, daquilo que era considerado velho e ultrapassado, ideologia muito presente no "Manifesto futurista".

Diante de tanta destruição com duas guerras mundiais na Modernidade, o mundo teve que se adaptar a conceitos mais instáveis como, por exemplo, os grandes avanços na ciência e na tecnologia, que contribuíram para o progresso da humanidade mas também poderiam levar à destruição através de bombas atômicas. Assim, o discurso rígido da Modernidade foi perdendo espaço para a flexibilidade pós-moderna.

Como afirma Rudinei Koop (2002, citado em Bauman, 2001), enquanto a Modernidade é sólida, a Pós-Modernidade é fluida. Aquilo que é sólido tende à permanência, está lidado ao espaço, ao território, não cede e muito menos se adapta a outras formas. Já os fluidos se movem facilmente. Eles fluem, escorrem, esvaem-se, respingam, transbordam, vazam, inundam, borrifam, pingam. 


\section{Das ruínas do moderno, o pós-moderno}

Enquanto a Modernidade se caracterizou pelo repúdio das antigas vanguardas tornando-se assim uma 'vanguarda do novo', a Pós-Modernidade é a 'vanguarda das vanguardas', consumindo, englobando e aceitando tudo e assim tornando-se um grande 'liquidificador pós-moderno', onde se podem encontrar 'fragmentos' de várias épocas. Apesar de também juntar avanços da Modernidade, a Pós-Modernidade pode-se entender como a negação da rigidez do pensamento moderno.

Na década de 1960 na França, os conceitos de Pós-Modernidade surgiram em trabalhos de autores como Foucault, Derrida, Deleuze, Rorty, Baudrillard e Saussure (Lucas, 2004). A partir de então um discurso mais flexível e de idéias que iam contra a exatidão do raciocínio moderno se tornou mais comum na lingüística.

Um fato importante para o surgimento da Pós-Modernidade é a mudança do centro econômico e intelectual mundial da Europa para os Estados Unidos. A fuga pós-guerra da comunidade européia para os Estados Unidos, aliada ao crescimento econômico americano gerado pela venda de recursos à Europa fizeram esse país tornar-se o novo centro do mundo. Assim nasce um território fértil para novas idéias.

Com a população cada vez mais rica, o consumismo tornou-se uma realidade norte-americana. Surge uma nova estética que está ligada à Pós-Modernidade, a estética Neokitsch. O consumo isento de necessidade e funcionalidade, buscando principalmente a satisfação pessoal de consumir, é característica do Neokitsch (Moles, 1971).

\subsection{Pós-linguagem}

A linguagem pós-moderna nasce de teorias lingüísticas contemporâneas, entre as quais se destacam: as teorias sobre novas estruturas textuais; a falta de linearidade narrativa; a descrença nas metanarrativas iluministas; o jogo de linguagem; a paródia; a valorização do significante acima do significado; a desconstrução da forma e da compreensão.

As teorias de Lyotard (1999) discutem os 'jogos de linguagens'. Afirmam que, apesar de o vínculo da sociedade ser lingüístico, essa ligação não se dá por uma via única e sim por vários e indeterminados caminhos que o autor chama de 'jogo de linguagens'. Cada indivíduo social faz uso de formas diferentes da linguagem comum a todos para o processo de comunicação.

O Estruturalismo e o Pós-estruturalismo de Ferdinand Saussure também são base da linguagem pós-moderna. São teorias que afirmam que a linguagem vem da complexa relação encontrada entre os signos, a relação entre o significado e o significante. Para Saussure, essa relação não se refere ao mundo real e a linguagem surge de questões internas da complexa relação entre signos. A parte principal do texto está na relação, na combinação e na trama entre significantes; adia, assim, o sentido do signo (Harvey, 2000).

O 'desconstrucionismo' de Jacques Derrida formou as bases para a comunicação instável. A desconstrução não é a destruição e sim a desmontagem dos elementos do texto. O processo de criar um texto está ligado ao cruzamento de vários textos que cria sentidos e resultados inesperados ao autor. Sendo assim, é inútil a tentativa do autor de dominar o texto; sua função é apenas atuar como meio da mensagem, pois a linguagem opera através deles. O leitor tem a função também criadora da mensagem final. Essa criação se dá através da montagem e da composição dos elementos do texto, desconstruídos (Harvey, 2000).

Diante da fragmentação da informação, da instabilidade da linguagem, a esquizofrenia surge como característica da comunicação na Pós-Modernidade. Jameson (1997) afirma que a esquizofrenia é o conflito lingüístico surgido da quebra na significação do sentido gerando informações sem conexões. São comunicados significantes que não têm relações entre si e impossibilita-se um significado. Isto se encaixa na preocupação pós-moderna, mais voltada ao significante do que ao significado.

Na produção cultural pós-moderna é fundamental a participação popular na obra, minimizando a autoridade de quem produz a comunicação. A desapropriação do autor deixa a obra aberta ao enriquecimento do olhar do espectador e gera significantes variados. O autor pós-moderno é aquele que propõe elementos, fragmentos que serão combinados segundo a visão do receptor. 


\section{Da forma ao ruído}

O design gráfico sofreu mudanças na passagem da Modernidade para a Pós-Modernidade, refletindo na parte gráfica o pensamento de cada período. No início do século XX, o progresso industrial moderno trouxe mais possibilidades ao design e o distanciou de estilos mais antigos como o Vitoriano, Artes e Ofícios e Art Nouveau. Surgiu o conceito determinante do design moderno: "less is more" ou "menos é mais". Depois, o design pós-moderno surge e agrega tudo rejeitado pela Modernidade, assim criando o "more is more".

As estéticas antigas, cheias de formas orgânicas e ornamentos, não se adequavam à nova geometria 'dura', industrial de massa, da Modernidade. As novas regras do design poderiam ser resumidas em simplificação e padronização da forma. São exemplos os cartazes sachplakat, que se resumiam à imagem do produto a ser vendido, mais o nome da empresa ou do produto.

Afirma Rudinei Koop (2002) que o pensamento do design moderno teve base no Construtivismo Russo, no De Stijl e na Bauhaus. Essas três escolas geraram um estilo visual que passou a ser seguido por designers de toda a Europa. A produção de impressos, principalmente cartazes, difundiu a construção visual por linhas ortogonais que prenunciava o conceito de grid ou malha módulo linear.

O Estilo Internacional suíço foi o ápice da padronização moderna. Depois da Segunda Guerra Mundial, o grande parque gráfico intacto era o norte-americano, que sentiu a necessidade de ter uma linguagem padrão para públicos multiculturais e buscou a solução no Estilo Internacional. A nova grande influência mundial americana fez do Estilo Internacional o novo padrão de design 'bom'. Grandes empresas tiveram contato com ele: a revista Vogue, a empresa de computadores IBM e a rede de televisão $A B C$.

O surgimento do design pós-moderno não tem linha divisória em relação ao moderno, pois não se pode afirmar que a base visual moderna foi abandonada. Porém, houve o crescimento de uma estética oposta à rigidez da primeira metade do século XX. O design pós-moderno surge da junção de trabalhos de escolas, estéticas de minorias e designers contrários ao Estilo Internacional.

O que estava sendo rejeitado não era a racionalidade da grade ou o uso de técnicas de solução de problemas; esses métodos continuaram sendo essenciais à produção dos gráficos de informação. $O$ modernismo, todavia, visto por seus defensores como 'livre de valores', especialmente por não ter referências históricas, havia conduzido o design a um formalismo árido e até mesmo a uma fórmula que muitos designers consideravam esgotada. (Hollis, 2001:202)

O Estilo Internacional reprimia a expressão visual de culturas diversas, mas começaram a surgir trabalhos de características próprias. Trabalhos da Push Pin Studio, da Academia de Arte Cranbrook, do grupo Grapus, do grupo Memphis, o estilo New Wave e o Punk começaram a criar uma nova estética. Havia visual cômico, abertura de várias interpretações, falta de legibilidades, desconstruções, ruído, sujeira, rasgões, fontes caligráficas ou de corpos e famílias diversas misturadas. Um 'prato cheio' para o ideal do 'mais é mais'.

\section{Televisão + Pós-Modernidade = MTV}

Foi no dia 20 de outubro de 1990, ao meio-dia, que a VJ Astrid Fontenele deu início às transmissões da rede de televisão brasileira, dizendo: "Oi, eu sou a Astrid e é com o maior prazer que estou aqui para anunciar para vocês que está no ar a MTV Brasil!". A MTV brasileira nasceu depois de nove anos da criação da similar norte-americana, graças à associação do grupo Abril com a Viacom dos Estados Unidos (MTV Brasil).

A MTV Brasil sempre abriu espaços para a participação popular na criação da programação da TV. A mais recente produção inovadora da MTV Brasil é a "Mega Liga MTV de Vjs Paladinos". É uma série de desenho animado em que os VJs da Music Television Brasil têm super-poderes. Foi através do espaço aberto para divulgação de animadores estreantes do programa "Gordo a GoGo" que se conheceu o trabalho do animador Pavão; este enviou uma animação onde o apresentador João Gordo lutava contra um ‘Engenheiro do Hawaii' gigante. 
A "Mega Liga MTV de Vjs Paladinos" é um desenho animado com referências de quadrinhos, cinema, outros desenhos animados, música, cultura popular e cultura cibernética. O programa é feito com orçamento baixo, contando apenas com a animação e ilustração caseira de Pavão e com o roteiro da MTV por Cacá Marcondes, gerente de núcleo da emissora. A série de desenhos animados é a primeira produzida por uma TV do Brasil e ganhou força em 2003 (Cruz, 2004).

\subsection{MTV, pós-TV}

A televisão é nova demais para se pensar que poderia existir um marco divisório entre a velha e a nova TV, mas o nascimento da MTV americana, em 1981, alterou a maneira de ver e fazer televisão, permitindo uma distinção entre TV e pós-TV. Além das grandes diferenças entre as velhas televisões e as MTVs do mundo, características da Pós-Modernidade são facilmente notadas na essência da Music Television.

Tendo nascido para ser uma televisão com programação focada em videoclipes, a MTV conseguiu tratar o meio audiovisual de maneira diferente. As outras TVs poderiam resumir-se em um meio que passa imagens com sons, mas a MTV podia traduzir-se em uma televisão que é 'imagem + música'. A música não só como pano de fundo, mas sim como elemento essencial da imagem. Existe uma simbiose tão forte entre música e imagem que não é possível dizer quem é o dominante (Coelho, 1996).

Por ser uma TV nova e que busca o público jovem, a MTV procura manter-se contemporânea, incorporando ou criando o que há de mais novo no meio audiovisual. É comum encontrar na programação da MTV novos videoclipes, desenhos animados um tanto diferentes, variados tipos de reality shows, apresentadores que têm maneiras muito esquisitas de fazer seus programas e vários espaços abertos para participação popular, em comparação com as outras TVs.

Uma característica pós-moderna que é essência da MTV é o multiculturalismo. Essa emissora se mostrou multicultural desde sempre, ao misturar culturas diversas com videoclipes de reggae jamaicano, do rock norte-americano e inglês, do funk dos afro-americanos e do punk inglês, entre outros. Atualmente esse multiculturalismo se encontra mais forte, já que existe uma Music Television em quase todos os países do mundo e ainda mais para minorias americanas específicas, como a MTV Country, a MTV Latina e a MTV Gay.

A MTV brasileira consegue manter um ambiente visual tão forte que exige de seu espectador uma ação dispersiva diferente das outras TVs. A quantidade de informação visual nas vinhetas cheias de desconstruções, imagens rápidas e chamadas com vários cortes de câmeras, ângulos diferentes do comum e fundos digitais é comum na MTV e gera um resultado visual que a distingue das outras TVs.

O ambiente visual criado pela MTV é forte, mas se sustenta, sobretudo, na instabilidade da imagem. A MTV não lida mais com a imagem, ou com o conceito tradicional de imagem, mas com algo que pode ser chamado de imagem molecular, animada por movimentos brownianos de cuja lógica apenas a teoria do caos pode prestar contas (Coelho, 1996).

A instabilidade é umas das características pós-modernas mais fortes no 'padrão' visual da MTV. Essa característica de imagem instável impera nas vinhetas institucionais da TV onde se pode encontrar o mínimo de padronização, que é a assinatura da marca da MTV. Contudo, a marca do canal foi o primeiro elemento gráfico cambiante da MTV e define muito bem o conceito dessa emissora.

\subsection{Identidade visual mutante}

Antes de entrar no ar, a MTV americana procurou um estúdio de design para criação de sua identidade visual que refletisse as idéias inovadoras da televisão. O "Manhattan Design" sugeriu, primeiramente, mudar o nome do canal de The Music Channel para Music Television. Então, através de um 'M' sem serifa com aspecto tridimensional e o 'TV' sobreposto com um estilo de grafitagem urbana, nasce a marca da MTV (Koop, 2002). Até então, não há nada de inovador. Porém, o elemento que traz a instabilidade visual e que define bem os conceitos buscados pela MTV foi o preenchimento cromático ou com texturas do ' $M$ ', que poderia ser cambiante e admitir infinitos resultados visuais.

O momento de insight ocorreu quando os designers realizaram o logo com um vasto conjunto de superfícies para o 'M' e o vigoroso 'TV', podendo ser alterado através de infinitas variações de cor, 
decorações, materiais, três dimensões, ângulos de visão e movimento. Ele pode tornar-se muitos objetos (um bolo de aniversário, uma embalagem de comida chinesa, um bloco de gelo). O logo pode assumir diferentes personalidades, participar de animações, assim pode ser demolido. O conceito de um logo com constantes alterações são contraria a segura e ampla crença de que marcas e identidades visuais devem ser fixadas absolutamente e usadas de modo consistente. Uma vez esse conceito decidido, o Manhattan Design produziu centenas de esboços para mostrar as possíveis variações. (Meggs, 1998:389)

As vinhetas institucionais da MTV, produtos que promovem a própria TV e servem para informar o canal em que estamos sintonizados, são as principais divulgadoras da instabilidade da identidade visual. Nessas vinhetas, a marca pode aparecer em preto e branco, vermelha, pequena, grande, em movimento, estática, em cortes rápidos, por um longo tempo, sozinha ou acompanhada por várias outras marcas iguais, variando de cor e formas dentro do ' $\mathrm{M}$ ', entre outras infinitas possibilidades que tornam rico o visual da emissora.

\subsection{Evolução visual da MTV Brasil}

No $11^{\circ}$ Encontro Nacional dos Estudantes de Design (Ndesign) em Recife, Jimmy Leroy, diretor de arte da MTV Brasil na época, afirmou que primeiramente quatro designers eram responsáveis pela programação visual da TV, em parceria com os diretores de Promo responsáveis pela direção dos programas. Antes disso, todo o material visual vinha da MTV norte-americana. Mesmo depois da criação de uma produção visual local mais dirigida ao público brasileiro, a MTV Brasil ainda seguiu o estilo visual da Music Television dos Estados Unidos (Credidio).

$\mathrm{Na}$ América do Norte, o estilo grunge influenciava a identidade visual das vinhetas da MTV. O grunge surgiu na década de 1990 e foi um movimento musical que teve como representantes bandas como "Alice in Chains", "Pearl Jam" e, principalmente, "Nirvana". Na linguagem visual, o grunge utilizou ruídos, ilegibilidade, formas orgânicas casuais como sujeira e rasgões. Tanto na moda como na linguagem visual, o movimento reincorporou características do punk. Como, nessa época, a recém-fundada Music Television brasileira importava suas vinhetas da matriz americana, pode-se afirmar que a MTV Brasil teve, primeiramente, uma identidade visual grunge inovador para o padrão visual televisivo brasileiro, e que logo conquistou a população underground brasileira.

Atualmente, o visual da MTV Brasil é cuidado pela equipe de 'Promo' (responsável pelas filmagens, produção, edição para vinhetas ou chamadas de programação) e a equipe de 'Gráficos' (responsável por ilustrações, marcas de programas, computação gráfica etc.). Por um longo período essas duas equipes estiveram sob o comando de Jimmy Leroy.

Em 1999, o visual da MTV mudou, no momento em que houve reformulação dos programas. As vinhetas fugiam da linguagem de cortes rápidos e tipografias desconstruídas, entre outras características visuais da MTV. Uma nova estética teve início na MTV Brasil e vem mudando a 'cara' da TV. Jimmy Leroy, no $11^{\circ} \mathrm{Ndesign}$, afirmou que houve uma evolução visual na TV para um design mais limpo, mais estudado, porém com alguma mistura do limpo com o trash. A reformulação visual do canal foi influenciada pela estética tecno, nascida do reflexo de uma linguagem eletrônica.

A estética tecno, encontrada na MTV, é mais um visual que nasce vindo de um estilo musical dos anos 90 e do começo do século XXI, das festas rave (Buccini, 2001). São características dessa estética as imagens $3 \mathrm{D}$ de computadores, bem como os coloridos que remetem às iluminações da raves, as imagens quadriculadas que valorizam o pixel digital, o blur do Photoshop, formas geométricas, tipografia sem serifa com cores chapadas e sem desconstruções. A vinheta do programa "Fica Comigo" foi um exemplo dessa estética.

Essa transformação visual que ocorreu na MTV Brasil é muito recente, por isso é errado afirmar que a estética tecno domina a linguagem visual do canal. Ela é encontrada em algumas vinhetas e chamadas e, até mesmo, em vinhetas institucionais da TV (Id's). Essa nova estética se mistura com outras e cria o visual contemporâneo da MTV Brasil. O que se pode dizer do surgimento da estética tecno na MTV é que o canal está sempre buscando se inovar - visual e conceitualmente - e ser tão jovem quanto seu público. 


\section{Infadesıg}

\section{Análise}

\subsection{Metodologia}

Com base nas características da linguagem e do design pós-modernistas estudados, buscouse destacar suas influências nas vinhetas institucionais da MTV (Id's). Algumas delas são: falta de linearidade narrativa, paródia, valorização do significante acima do significado, desconstrução, fragmentação, turbulência visual, cortes rápidos, ruído, mistura de linguagens do presente e do passado (Retro) como também a estética de videoclipes e videoarte.

As vinhetas foram capturadas do sinal aberto da MTV que chega às casas no período de junho de 2004 a fevereiro de 2005. Algumas novidades que ocorreram nessa passagem de ano nas vinhetas institucionais do canal, como o aparecimento de seqüências, também serão destacadas e analisadas. Deu-se destaque à análise de como a marca da MTV é usada nas vinhetas, pois é com a assinatura da marca MTV que se pode afirmar que essas vinhetas são produtos promovedoras da empresa televisiva estudada.

\section{Vinheta 1}
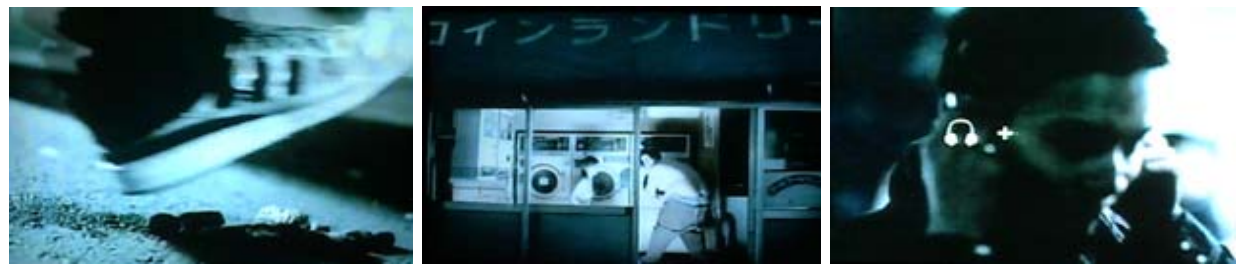

Mostra um jovem asiático escutando um walkman, carregando algumas sacolas e andando pelas ruas de alguma cidade asiática. Uma possível explicação do que ocorre seria que o jovem está cheio de problemas, como fala umas das estrofes da música na vinheta de Moby, "Natural Blues": "... oh lordy, trouble so hard; don't nobody know my troubles but god ...", "...Oh Deus, problemas tão difíceis; ninguém sabe meus problemas, só Deus".

Há uma linguagem de videoclipe, pois a música e a imagem dão o ritmo da vinheta, slow motion. Há uma quebra nesse ritmo quando o fone do walkman sai de seu ouvido, permitindo que se escutem os sons da cidade. Depois, o rapaz coloca o walkman de volta e o ritmo antigo da vinheta retorna, como também o estado de relaxamento expressado em seu sorriso.

Nesse momento final de valorização musical, faz-se referência a uma expressão muito utilizada pela Music Television: (música + televisão = MTV). Mas nesta vinheta a expressão é: (ícone de fone de ouvido + o rapaz que está escutando a música $=M T V$ ). Esse final da vinheta mostra que a MTV é formada por música e principalmente por aqueles que gostam de música, seus telespectadores.

\section{Vinheta 2}
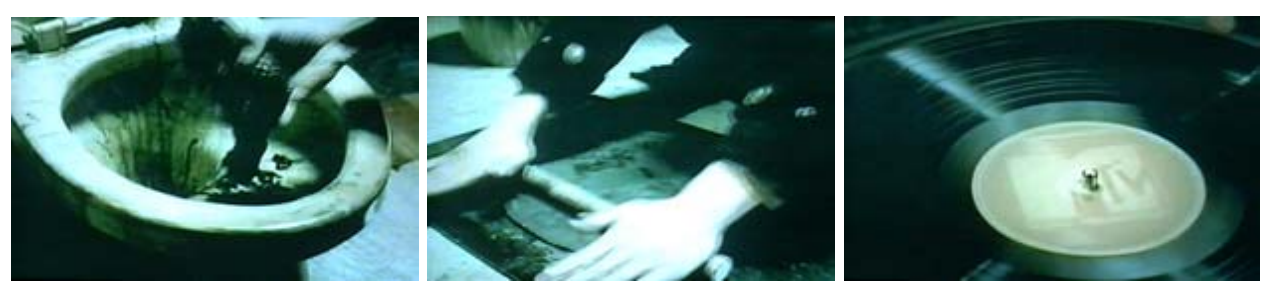

Mostra um rapaz que pega suas fezes de um vaso sanitário e faz, a partir disso, um disco de vinil que é colocado para tocar. Aparece, no centro do disco, a marca MTV em branco, com tonalidade marrom.

A vinheta tem estética punk, caracterizada pela sujeira distribuída nas paredes, pelo chão e pelo vaso sanitário, e pelo visual do rapaz que, apesar de ser oriental, tem cabelo arrepiado como os moicanos dos punks. A fotografia tem poucas cores, com predominância da tonalidade marrom. Há uma temática chocante, como nas músicas e fanzines punks, por abordar fezes humanas 
como o principal elemento visual. Outra característica dessa cultura underground é o "do yourself", "faça você mesmo", considerando que o rapaz faz um vinil vindo de seus excrementos.

Como muitas vinhetas institucionais do canal brasileiro, essa não tem interpretação única e inflexível, sendo assim possível entendê-la de diversas formas diferentes. Como vimos, as obras pós-modernas necessitam e buscam a visão do espectador, que as torna menos autorais e tão diversificadas quanto forem as interpretações de quem as vê.

\section{Vinheta 3}
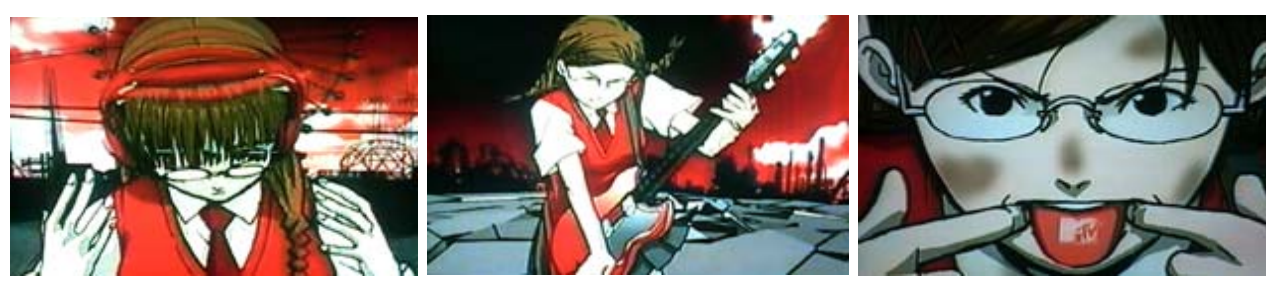

Há uma menina em um parque de diversões fazendo remix em uma mesa de som, e caixas de som ascendem do chão. Depois, com uma guitarra, ela dá uma nota aguda e faz a caixa de som explodir. Então, em meio à explosão, surge a menina mostrando a língua, que tem a marca da MTV em branco.

O ritmo da vinheta é acelerado, cheio de cortes de câmera. São 21 cortes em 13 segundos, uma média de três cortes a cada dois segundos. A linguagem do corte de câmera é tão utilizada que no lugar de dar um simples zoom in, no final da animação, por exemplo, existe um corte de um plano mais aberto para um mais fechado.

A estética da vinheta mistura imagens e desenhos bidimensionais com tridimensionais e vídeos reais. O traço do desenho com duas dimensões e os movimentos da garota têm o estilo de desenhos orientais de anime. A vinheta tem uma narrativa despretensiosa, sem grandes interpretações, contudo é possível observar que a música é o seu tema central, com guitarra, caixa de som e mesa de som.

\section{Vinheta 4}
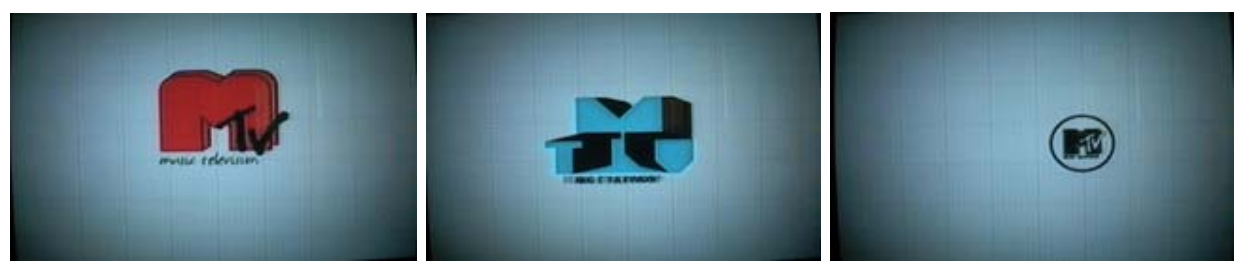

São mostradas as letras ' $M$ ', 'T' e 'V' aparecendo e sumindo com formas e cores diferentes. Nessa vinheta é presente a instabilidade. São sete combinações visuais de letras e duração total de 14 segundos. Apesar de a mensagem fonética ser sempre a mesma, com três letras e duas palavras, a mensagem visual está sempre em mudança. As letras apresentam cores, formas, estilos e movimentos variados o tempo todo, havendo uma valorização tipográfica.

A vinheta é um exemplo da estética tecno presente na linguagem visual da emissora. É característica dessa linguagem na animação a presença de um visual limpo, com tipos arredondados, cores chapadas, formas tridimensionais, ausência de ruídos visuais e referência à linguagem visual de computadores. 


\section{Vinheta 5}
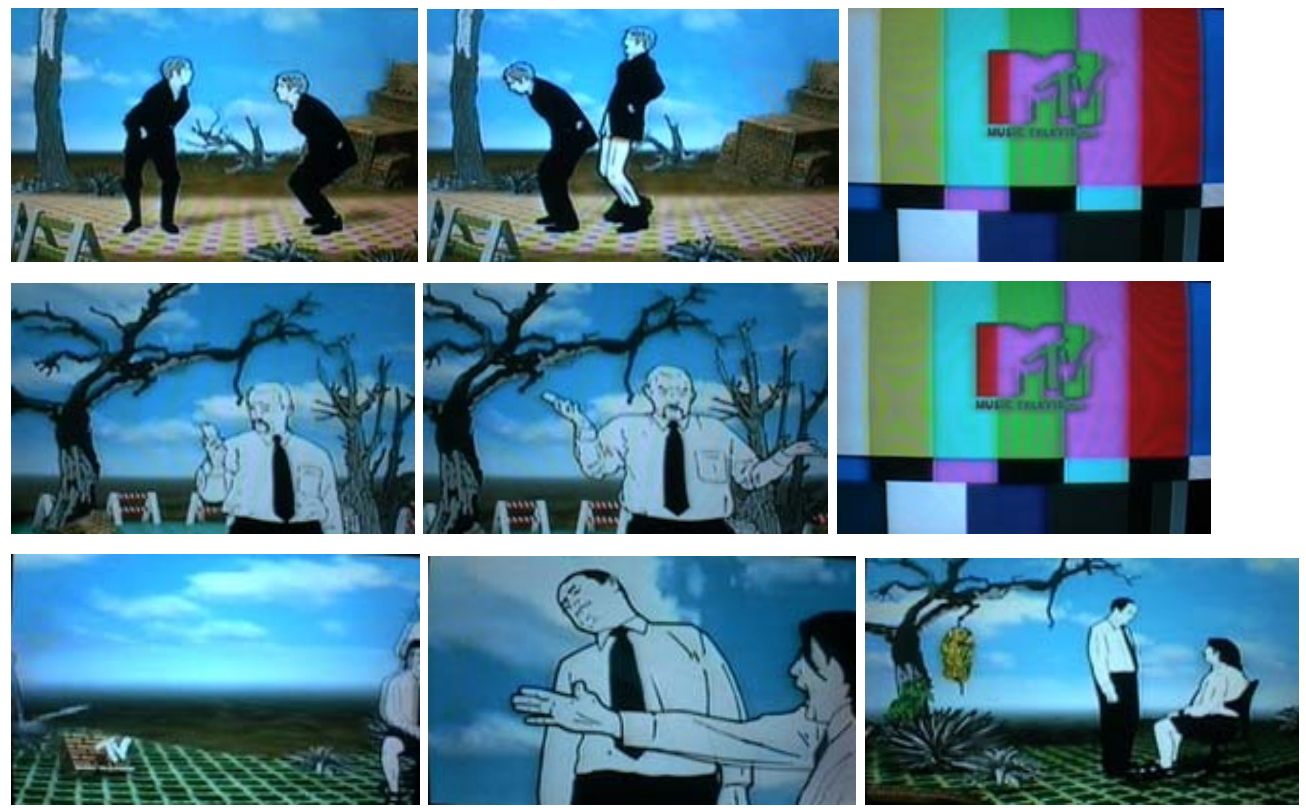

Depois do início de 2005, tornaram-se comuns vinhetas seqüenciadas que formam uma série na programação da MTV Brasil. Apesar de não seguirem um padrão, existem alguns elementos, principalmente gráficos, que as tornam uma seqüência. São narradas três histórias de temas diferentes. Na primeira vinheta, há uma comunicação entre dois homens vestidos com ternos; eles se movem e piam como pássaros, em vez de falar. Na segunda, um homem acorda para atender ao seu celular, porém ele late como um cão. A terceira vinheta mostra dois homens, um sentado e outro mexendo em seu cabelo, o que acaba em uma briga de tapas.

São características das três vinhetas as pessoas em desenhos feitos sobre um vídeo gravado com pessoas reais (rotoscopia). Nas três vinhetas há, também, troncos de árvores secas, tijolos e chão de azulejo caracterizando um cenário surrealista.

A marca da MTV aparece grande, bem visível no centro da tela e com cores complementares do colorbar, ou com textura de tijolos e aspecto tridimensional no início da vinheta da briga de tapas. As três vinhetas fazem a exposição de vários significantes sem preocupação com o significado, o que caracteriza uma linguagem esquizofrênica.

\section{Vinheta 6}
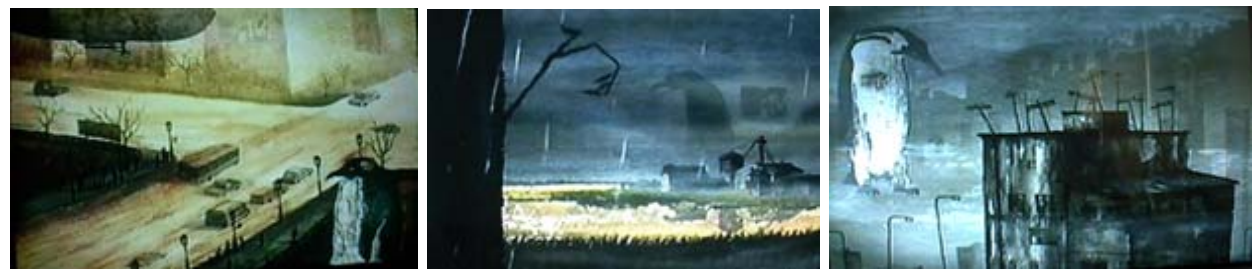

A vinheta é uma série alternada pela programação da TV. Vê-se um pingüim em variados cenários do campo e do centro urbano. A principal característica desta vinheta é a melancolia, que se encontra principalmente na música de piano e nas expressões tristes, de cabeça baixa, do pingüim. As poucas cores também ajudam a compor essa tristeza visual.

Os elementos desta animação são confusos e dificultam sua compreensão visual. É característico o uso de transparências e imagens enfumaçadas, que criam um aspecto borrado. Até mesmo a marca da MTV aparece quase imperceptível, em marrom, como se fosse uma sujeira na parede de um prédio.

Uma qualidade desta vinheta é que ela é sempre alterada. Colocam-se fragmentos desta versão mais longa na programação da MTV, mas os acontecimentos são alterados. Uma das principais mudanças é a maneira como a marca da MTV aparece em lugares diferentes da versão principal. 


\section{Conclusão}

Percebeu-se que as vinhetas não seguem uma unidade. Pode haver vinhetas com linguagens de videoclipes, videoarte, animação japonesa, animação tipográfica ou animação que se mistura com cenas reais de vídeo. Encontram-se várias técnicas de criação no campo audiovisual explorando todas as possibilidades de linguagem para vídeo, o que torna cada vinheta uma peça gráfica única.Também há referências a várias estéticas, como a estética punk que aparece na vinheta do jovem criando um vinil e a tecno na animação tipográfica. A estética japonesa dos animes se encontra na terceira vinheta, e a influência da estética surrealista na quinta.

A marca da MTV também aparece de diversas formas. Apenas nessas seis vinhetas a marca da MTV apareceu com o preenchimento branco e tonalidade marrom, com barras de cores vermelha e azul, com textura de tijolos tridimensionais, preta, branca e marrom borrado, quase ilegível.

Também ocorreu uma instabilidade no destaque da marca da MTV nas vinhetas. Ela pode aparecer muito pequena ou com pouca evidência visual, como nas vinhetas 1 e 6 , pequena porém se destacando por movimento ou sons como nas vinhetas 3 e 4, tamanhos médios como na 5 , ou grande como na 2 e 6 . É como se a marca da MTV fosse um elemento gasoso, que consegue se encaixar em várias formas e ter volumes indeterminados.

Uma das principais características destas vinhetas da MTV e de outras que sempre estão na programação do canal é sua linguagem não objetiva. As várias interpretações de uma mesma vinheta pelo público são o resultado dessa falta de clareza no que está sendo dito nas vinhetas. Contudo, percebe-se a pretensão de explorar a capacidade imaginativa dos telespectadores.

Essas vinhetas não divulgam só a identidade visual da MTV pela sua marca, também mostram "quem a MTV é". A abertura para que o público também possa interagir na criação dessas vinhetas faz que a linguagem da emissora seja tão diversificada quanto elas. Mas será que as vinhetas das MTV são trabalhos artísticos que refletem a expressão pessoal, já que muitas delas são feitas pelos telespectadores ou são vinhetas que promovem a empresa? Elas são videoarte ou vídeos institucionais? Como vimos, essas dicotomias não são características da PósModernidade. A MTV, como uma televisão pós-moderna, mostra que essas vinhetas podem ser os dois ao mesmo tempo.

Também se deve observar que essa linguagem adotada pela MTV é bem aceita porque seu público é composto por jovens de classe média e alta que apreciam músicas vindas principalmente dos estilos derivados do rock. O universo de espectadores do canal tem simpatia pelo diferente, contestador, agressivo etc.

Todas as características encontradas nas vinhetas da MTV Brasil - como fragmentação da informação, mistura de estilos antigos com novos, preocupação maior com o significado, multiculturalismo - definem bem o visual desse canal, mas as principais características delas são a falta de padronização, a falta de obediência a regras rígidas e a exploração de diversas possibilidades de se fazer um vinheta. Apesar de toda essa flexibilidade de linguagem, elas ainda mantêm muito bem a função básica de uma vinheta institucional, a de promover a televisão e ressaltar ao telespectador qual é o canal a que ele está assistindo. Com toda essa linguagem que se modifica sempre, a MTV mostra sua essência de ter várias caras, como seu público, e de ter uma estética pós-moderna.

\section{Referências}

Buccini, Marcos. (2001) A estética tecno na tipografia de vinhetas da MTV. s.l. Disponível em: http://www.notitia.com.br/milanesa/newstorm.notitia.apresentacao.ServletDeNoticia?codigoDaN oticia=342\&dataDoJornal=atual. Acesso em: 3 fev. 2005.

Coelho, Teixeira. (1996) Moderno pós-moderno. 3.ed. São Paulo: Iluminuras.

Credidio, Diego. (2001) Jimmy Leroy. s.I. Disponível em: http://www.notitia.com.br/milanesa/newstorm.notitia.apresentacao.ServletDeNoticia?codigoDaN oticia=2041\&dataDoJornal=atual. Acesso em: 3 fev. 2005.

Cruz, Ricardo. (2004) Animação geral. Revista da MTV, São Paulo, v.IV, n.34, p.66-69, março. 


\section{Infodesıgn}

Harvey, David. (2000) A condição pós-moderna: uma pesquisa sobre as origens e mudanças sociais. São Paulo: Loyola.

Hollis, Richard. (2001) Design gráfico: uma história concisa. São Paulo: Martins Fontes.

Jameson, Fredric. (1997) A lógica cultural do capitalismo tardio. 2.ed. São Paulo: Ática.

Koop, Rudinei. (2002) Design gráfico cambiante. Santa Cruz do Sul (RS): Edunisc.

Lucas, Fábio. (2004) No rastro da pós-modernidade. Continente multicultural, Recife, v.IV, n.42, p.76-79, junho.

Lyotard, Jean-François. (1998) A condição pós-moderna. 5.ed. Rio de Janeiro: J. Olympio Ed. Machado, Arlindo. (2000) A arte do vídeo. 2.ed. São Paulo: Brasiliense.

Meggs, Philip B. (1998) A history of graphic design. 3.ed. New York: Jonh Wiley \& Sons.

Moles, Abraham (1971). O kitsch. 5.ed. Trad. Sergio Miceli. São Paulo: Perspectiva. 232p. (Coleção Debates).

MTV Brasil. (2002) História da TV. s.I. 2002. Disponível em: http://www.tudosobretv.com.br/histortv/historbr.htm\#. Acesso em: 7 jan. 2005.

\section{Sobre o autor}

\section{Guilherme Lyra}

Graduado em Design pela Universidade Federal de Pernambuco em 2005, quando ganhou o Prêmio Gastão de Holanda por ter realizado um dos melhores projetos de graduação de 2004, "MTV, a única com design pós-moderno".

lyraguilherme@gmail.com 